\title{
Fruit and vegetable intakes and sources in Irish pre-school children (1-4 years): The National Pre-School Nutrition Survey
}

\author{
L. Keyes, A. Connaughton, M. O’Reilly, J. Walton and A. Flynn \\ School of Food and Nutritional Sciences, University College Cork, Cork, Republic of Ireland
}

Fruit and vegetable intakes play an important role in the prevention of chronic diseases ${ }^{(1)}$. Early childhood is a pivotal time in the development of food preferences and as such an opportunity to foster the development of healthy eating practices. There is however limited data on fruit and vegetable intakes in young children. The importance of composite foods in the estimation of fruit and vegetable intakes has been previously highlighted, albeit in adults ${ }^{(2)}$.

The objective was to estimate fruit and vegetable intakes, including those from composite foods, and identify the sources, in Irish preschool children aged 1-4 years using data from the National Pre-School Nutrition Survey (NPNS).

The NPNS (2010-2011) was carried out to establish a database of habitual food and drink consumption in a representative sample of Irish pre-school children aged 1-4 years. A 4-d weighed food record was used to collect food intake data from 500 pre-school children. 740 of 1652 food codes consumed, had a fruit/vegetable component. These included discrete fruit and vegetables and fruit and vegetables incorporated in composite foods. The percentage of fruit and/or vegetables in each of these food codes was estimated using standard recipes from McCance and Widdowson's, The Composition of Foods ${ }^{(3-4)}$, from participants' food diaries, and manufacturers' product information. Calculations were included to remove inedible portions and to account for the effects of concentration e.g. in the case of tomato purée.

Almost all pre-school children consumed fruit and vegetables. Fruit contributed $15 \%$ and vegetables contributed $5 \%$ to the total weight of food and beverages in the diet and did not vary significantly with age. Intakes and sources of fruit and vegetables are displayed in the below table, examined by age.

\begin{tabular}{lccccc}
\hline & $\begin{array}{c}\text { Age 1 yr } \\
(n=126)\end{array}$ & $\begin{array}{l}\text { Age 2 yrs } \\
(n=124)\end{array}$ & $\begin{array}{c}\text { Age 3 yrs } \\
(n=126)\end{array}$ & $\begin{array}{c}\text { Age 4 yrs } \\
(n=124)\end{array}$ \\
\cline { 2 - 5 } & \multicolumn{5}{c}{ Mean Intake (g/d) } \\
\hline Total Fruit & $\mathbf{1 5 1}$ & $\mathbf{1 8 5}$ & $\mathbf{2 0 9}$ & $\mathbf{2 1 3}$ & 0.000 \\
Discrete fruit & 84 & 102 & 105 & 102 & 0.000 \\
100\% fruit juice, smoothies, purées & 48 & 61 & 86 & 96 & 0.002 \\
Fruit in composite foods & 19 & 22 & 18 & 15 & 0.504 \\
Total vegetables & $\mathbf{6 3}$ & $\mathbf{5 3}$ & $\mathbf{5 3}$ & $\mathbf{6 1}$ & 0.184 \\
Discrete vegetables & 30 & 28 & 31 & 38 & 0.065 \\
Vegetables in composite foods & 33 & 25 & 22 & 23 & 0.001 \\
\hline
\end{tabular}

Intakes of total fruit increased with age, in particular intakes of fruit juice. The sources of total fruit intake were: discrete fruit (47-56\%) of which bananas (14-19\%) and apples (7-13\%) contributed the most, 100\% fruit juice, smoothies and purées (32-45\%) and fruit in composite foods (7-13\%). Total vegetable intakes comprised of discrete vegetables (48-62\%) of which peas, beans and lentils (11-16\%) and carrots $(9-15 \%)$ contributed the most and vegetables in composite foods (38-52\%) of which meat based dishes (15-30\%) were the most consumed.

In conclusion, fruit and vegetables are important components of the diet of Irish pre-school children. Total fruit intakes increased with age including intakes of discrete fruit and juice, smoothies and purées. Total vegetable intakes did not change with increasing age although the proportion from composite foods decreased.

The project was funded by the Irish Government under the Food and Health Research Initiative 2007-2012.

1. WHO Technical Report, Series 916 Diet, Nutrition \& the Prevention of Chronic Disease (2003).

2. O'Brien et al. (2003) Public Health Nutr 6(7): 711-26.

3. Food Standards Agency, 2002.

4. Holland et al. Royal Society of Chem. \& Ministry of Agriculture, Fisheries \& Food. London:HMSO, 1995. 